\title{
Determination of the base plate stiffness and strength of steel storage racks
}

Benoit P. Gilbert ${ }^{\mathrm{a} *}$, Kim J.R. Rasmussen ${ }^{\mathrm{b} * *}$

${ }^{\mathrm{a}}$ Previously, School of Civil Engineering, The University of Sydney, Sydney, NSW 2006, Australia. Present, School of Engineering, Griffith University, Gold Coast, QLD 4222, Australia.

${ }^{\mathrm{b}}$ School of Civil Engineering, The University of Sydney, Sydney, NSW 2006, Australia

* Phone: +61 75552 8577, E-mail: b.gilbert@griffith.edu.au (corresponding author)

** Phone: +61 29351 2125, E-mail: kim.rasmussen@sydney.edu.au

\section{ABSTRACT}

This paper addresses the problem of determining the stiffness and strength of steel storage rack base plate assemblies. Base plate assemblies are usually bolted to an upright and to a concrete floor, and used to provide resistance against the flexural buckling of the upright and/or the overall down-aisle buckling of the frame. The semi-rigid stiffness is usually determined by means of a test of two pre-loaded uprights connected to a concrete block in a dual-actuator set-up. Guidance for conducting the test is provided in the European Standard EN 15512. However, several aspects of the test need clarification, notably the test set-up and the transducer arrangement for measuring the rotations of the base plate. This paper provides recommendations for how best to conduct the test, and proposes an alternative test method to that given in the EN 15512 Specification.

The paper also identifies the contributions to the deformations of base plate assemblies, including the deformations of the supporting floor, the base plate assembly itself and the upright, and proposes simple expressions for calculating the stiffness associated with each contributing deformation where applicable. Furthermore, the paper proposes a deformation criterion for determining the ultimate design moment for base plate tests which do not attain a peak moment.

Keywords: Steel structure, Steel storage rack, Base plate test, Design, Experiment 


\section{Introduction}

Steel storage racks are used extensively in the manufacturing industry to store goods. Goods are placed on pallets which are positioned on the rack using forklift trucks. Storage racks are versatile structures capable of accommodating client needs in terms of access, capacity and space. They are mainly made from cold-formed steel profiles. Typically, the connection between the floor and the columns, referred to as uprights, is achieved by means of a base plate assembly. The assemblies are usually, but not always, bolted to the floor. A typical storage rack is shown schematically in Fig. 1.

The stability of a storage rack is dependent on the beam to column connection stiffness [1] and the base plate stiffness [2, 3]. Both stiffness values are typically used in structural analysis models employed to design the storage rack and accurately determining these stiffness is therefore important to achieve economical designs. A linear or non-linear moment-rotation relationship is usually chosen to model the base plate connection.

Two main specifications deal with storage rack design and have different approaches to determining the base plate stiffness. The Rack Manufacturers Institute (RMI) Specification [4] uses an equation for the base plate stiffness based on the base plate dimensions and the modulus of elasticity of the floor. The European Standard EN 15512 [5] recommends testing to determine the base plate stiffness, the stiffness being derived from the maximum observed moment. A test set-up is suggested in the EN 15512 [5] Specification, however, several aspects of the test need clarification, including the test set-up and the transducer arrangement required to measure the rotation of the upright relative to the floor. This paper analyses the different components affecting the base plate stiffness and gives recommendations for the location of the transducers when performing base plate tests to the EN 15512 [5] Specification. Two alternative base plate test set-ups are investigated. The merits of both test set-ups are discussed, concluding that one alternative is superior to the other.

Moreover, tests performed in the School of Civil Engineering at the University of Sydney, based on the test set-up suggested in the EN 15512 [5] Specification, show that for low axial loads in the upright section, no maximum bending moment can be reached under large deformations, leading to difficulties in calculating the base plate stiffness using the EN15512 [5] guidelines.

This paper also proposes an alternative to determining the maximum bending moment based on the ultimate deformation when no maximum bending moment can be reached. Stiffness values obtained from tests are compared to stiffness values obtained using available 
guidelines, and recommendations are made for the pre-design of storage racks when base plate stiffness tests results are unavailable.

FE analyses are performed of the base plate assembly used in the experimental tests and, for this particular assembly, conclusions are drawn about the variation of the base plate initial stiffness and strength with the upright width.

\section{Base plate behaviour}

Storage racks are connected to the floor by the use of base plate assemblies. The assemblies are designed to transmit axial forces and moments to the floor. Typically, their momentrotation stiffness and strength depend on the axial force in the upright [6]. The upright section can either be bolted or connected by means of tabs to the base plate assembly, which is usually bolted to the floor. An example of a base plate assembly, similar to the base plate assembly investigated in this paper, is shown in Fig. 2.

\subsection{Base plate deformation}

The deformation of a base plate assembly subjected to an applied moment can be broken into four main components. Each of these deformations contributes to the total rotation of the upright and may not be prominent at the same time. The concrete block under the base plate will deform locally (Fig. 3 (a)), the bracket of the base plate assembly will bend (Fig. 3 (b)), the upright itself will bend and rotate relative to the base plate assembly (Fig. 3 (c)), and a combination of flexure and yield lines will form in the base plate allowing the assembly above the base plate to rotate as a rigid body (Fig. $3(\mathrm{~d})$ ).

\subsection{Transducer location}

In the base plate test set-up shown in the EN 15512 [5] Specification, two Linear Variable Differential Transformers (LVDT) are positioned on either side of the upright to measure its rotation as shown in Fig. 4 which reproduces the test set-up (Figure A.11 in Section A.2.7.2 of the EN 15512 [5] Specification). However, the precise position of these transducers is not specified. Several base plate tests can be found in the literature $([7,8])$ but they do not specify the chosen location of the transducers, calling for clarification and standardization of the transducers location.

In a structural analysis model, the base plate assembly will be either modelled as a connection element or node with linear or non-linear properties. The properties are based on the measured 
moment-rotation response, and hence, the measured rotation should include all four components of rotation introduced in Section 2.1. It is therefore important that the transducers be placed such that they capture all components of rotation over the length of the base plate assembly and not more.

In view of the contributions to rotation shown in Fig. 3, to capture the total rotation of the upright, the transducers should be located just above the boundary between the base plate assembly and the upright. Indeed, having the transducers below this line will only partially measure the rotation of the upright and having the transducers well above this line will include flexural deformations of the upright and lead to conservative results for the stiffness. Fig. 5 shows an appropriate position for the transducers to accurately capture the rotation of the upright when performing base plate tests.

\section{Base plate test set-up}

The EN 15512 [5] Specification recommends a range of axial loads be used in determining the base plate assemblies rotational stiffness and strength. A test set-up is suggested in Section A.2.7.2 of the Specification and the associated Figure A.11 of the Specification is reproduced in Fig. 4. However, it is permitted to use an alternative test set-up if the alternative method “accurately models the real structural condition”.

In the proposed dual-actuators test arrangement, two lengths of upright at least four times the upright width are symmetrically connected to a concrete block representing the floor, as shown in Fig. 4. Standard base plate assemblies are used and connected to the concrete block using standard fixing devises. Two jacks apply load to the structure, jack $\mathrm{n}^{\mathrm{0}} 1$ simulates the axial load in the upright while jack $\mathrm{n}^{0} 2$ applies a lateral force on the concrete block to create a moment in the base plate assembly. As stipulated in the specification, at the beginning of the test, the load $F_{1}$ is increased in jack $n^{0} 1$ to the desired axial load and kept constant during the test. The load $F_{2}$ in jack $n^{0} 2$ is then gradually increased until the load reaches a maximum. The EN 15512 [5] Specification stipulates that the concrete block must be free to move in the horizontal plane but restrained from rotating about its vertical axis. However, restraining the block from rotating about its vertical axis and having a pin between the block and jack $\mathrm{n}^{\mathrm{0}} 2$, as shown in Fig. 4, is inconsistent.

In view of this inconsistency, two methods were tested in the Structures Laboratory of the School of Civil Engineering at the University of Sydney. Method 1 had a pinned connection between the concrete block and jack $\mathrm{n}^{0} 2$, allowing the concrete block to rotate about its 
vertical axis. In Method 2, the concrete block was connected to jack $\mathrm{n}^{0} 2$ in a way which restrained its rotation about its vertical axis but allowed displacements in the horizontal plane. The two methods and the associated formulae to obtain the moment-rotation curves are explained hereafter. Results obtained from the two methods are discussed, concluding that Method 2 is superior to Method 1.

\subsection{Method 1}

The test arrangement for Method 1 is in accordance with Figure A.11 of the EN 15512 [5] Specification (see Fig. 4), using a pinned connection between jack $\mathrm{n}^{\mathrm{o}} 2$ and the concrete block. The concrete block is free to move in the horizontal plane and free to rotate about its vertical axis, as illustrated in Fig. 6 (a) in which the connection between the concrete block and jack $\mathrm{n}^{\mathrm{o}} 2$ is achieved by a frictionless half-round, allowing negligible shear to be transmitted to jack $\mathrm{n}^{\mathrm{o}} 2$. Grease was used between a steel plate connected to the concrete block and the half round to limit friction between the two surfaces. The moment-rotation formulae are given in Eqs. (1)-(4), derived in accordance with Fig. 7 (a) with reference to the test set-up illustrated in Fig. 6 (a).

Assuming that the transducers measure displacements relative to a fixed reference, the rotation $\theta_{\mathrm{b}, \mathrm{i}}$ of each base plate relative to the concrete block is given by,

$$
\begin{aligned}
& \theta_{b, 12}=\theta_{12}-\theta_{56}=\frac{\delta_{1}-\delta_{2}}{d_{12}}-\frac{\delta_{5}-\delta_{6}}{d_{56}} \\
& \theta_{b, 34}=\theta_{34}+\theta_{56}=\frac{\delta_{4}-\delta_{3}}{d_{34}}+\frac{\delta_{5}-\delta_{6}}{d_{56}}
\end{aligned}
$$

where $\theta_{12}, \theta_{34}$ and $\theta_{56}$ are the rotations of the right base plate, left base plate and the concrete block relative to a fixed reference, respectively (see Fig. 7), $\delta_{\mathrm{i}}$ represents the displacement of transducer $i$ in Fig. 6 and $d_{\mathrm{jk}}$ represents the distance between transducers $j$ and $k$ in Fig. 6 . The second order moments $\mathrm{M}_{\mathrm{i}}$ applied to each base plate are given by,

$$
\begin{aligned}
& M_{12}=\frac{F_{2} L}{4}+F_{1}\left(\Delta-\frac{\theta_{56} L_{c}}{2}\right) \\
& M_{34}=\frac{F_{2} L}{4}+F_{1}\left(\Delta+\frac{\theta_{56} L_{c}}{2}\right)
\end{aligned}
$$

where $L$ and $L_{C}$ are twice the length of a upright section including the rigid hinge connected to the upright and the width of the concrete block, respectively (see Fig. 6), and $\Delta$ is the displacement of the concrete block as shown in Fig. 7, obtained as, 


$$
\Delta=\frac{\delta_{5}+\delta_{6}}{2}
$$

In this test, it is likely that one base plate will fail before the other. The rotation of this particular base plate will continue to increase and a plastic hinge will eventually form, leading to a plastic collapse mechanism. The rotation in the other base plate will essentially stop or revert to elastic unloading, causing the concrete block to rotate. Results discussed later will show this phenomenon. Due to the asymmetrical behaviour at failure, only one momentrotation curve out of two can be used for determining the base plate stiffness (the one which fails) and no average moment-rotation curve can be calculated.

\subsection{Method 2}

The test arrangement for Method 2 is shown in Fig. 6 (b). The concrete block is connected to jack $\mathrm{n}^{0} 2$ using rigid plates and bolts to prevent its rotation. The holes in the plate connected to jack $\mathrm{n}^{\circ} 2$ are slotted, allowing it to slide relative to the plate bolted to the concrete block, and the bolts are loosely tightened so as to minimise the shear force transmitted between the concrete block and jack $\mathrm{n}^{0} 2$. Special care is taken to restrain the rotation of jack $\mathrm{n}^{0} 2$ by applying a lateral restraint to the jack near the connection to the concrete block.

Referring to Fig. 6 (b) and Fig. 7 (b), the rotation $\theta_{b, i}$ of each upright is given by,

$$
\begin{aligned}
& \theta_{b, 12}=\theta_{12}=\frac{\delta_{1}-\delta_{2}}{d_{12}} \\
& \theta_{b, 34}=\theta_{34}=\frac{\delta_{4}-\delta_{3}}{d_{34}}
\end{aligned}
$$

The second order moments $\mathrm{M}_{\mathrm{i}}$ applied to each base plate are given by,

$$
\begin{aligned}
& M_{12}=\frac{F_{2} L}{4}+\frac{M_{R} L}{4\left(L+L_{C}\right)}+F_{1} \Delta \\
& M_{34}=\frac{F_{2} L}{4}-\frac{M_{R} L}{4\left(L+L_{C}\right)}+F_{1} \Delta
\end{aligned}
$$

where $M_{R}$ is the moment exerted by the restraining system, as shown in Fig. 7 (b).

By restraining the concrete block from rotating about its vertical axis, it is possible for both base plates to fail. The average rotation $\theta_{b}$ of the base plates and the average moment $M_{b}$ applied to the base plates can thus be calculated,

$$
\theta_{b}=\frac{1}{2}\left(\theta_{12}+\theta_{34}\right)=\frac{1}{2}\left(\frac{\delta_{1}-\delta_{2}}{d_{12}}+\frac{\delta_{4}-\delta_{3}}{d_{34}}\right)
$$




$$
M_{b}=\frac{1}{2}\left(M_{12}+M_{34}\right)=\frac{F_{2} L}{4}+F_{1} \Delta
$$

Eqs. (10)-(11) are identical to the equations given in Section A.2.7.3 of the EN 15512 [5] Specification. Photographs of the test set-up for Method 2, including the restraining system are shown in Fig. 8.

\subsection{Results and comparison}

Method 2 allows both base plates to fail and thus the moment-rotation curve becomes an average of the moment-rotation curves of the two base plates. Statistically, the mean curve is a better result than the single lower-bound curve Method 1 produces when a pin is used between the concrete block and jack $\mathrm{n}^{0} 2$.

Moreover, it is essential to perform the test with jack $n^{0} 2$ driven in displacement control, while jack $n^{0} 1$ is best driven in load control. Method 2 readily allows the test to reach and pass the maximum bending moment when jack $\mathrm{n}^{0} 2$ is driven in displacement control because the rigid connection between jack $\mathrm{n}^{0} 2$ and the concrete block allows the transfer of both compressive and tensile forces. On the contrary, in Method 1, unless the pinned connection between jack $\mathrm{n}^{\mathrm{o}} 2$ and the concrete block is designed to transfer tension, a catastrophic failure will occur when, under large displacements, the lateral load changes from compression to tension and therefore, tests reported in the literature are often stopped before reaching the maximum bending moment. For these reasons, Method 2 is superior to Method 1. Two tests at an axial load of $100 \mathrm{kN}$ were performed with a pinned connection between jack $\mathrm{n}^{0} 2$ and the concrete block (Method 1). Fifteen tests at axial loads equal to $0 \mathrm{kN}, 33 \mathrm{kN}, 100$ kN, $150 \mathrm{kN}$ and $200 \mathrm{kN}$ were performed (three tests per axial load) with the concrete block restrained from rotating (Method 2). Upright and base plate assembly characteristics are given in Table 1.

The results obtained using Method 1 are shown in Fig. 9 (a) for the two tests. Both $\mathrm{M}_{12}$ and $\mathrm{M}_{34}$ determined from Eqs. (3)-(4) are plotted. For test 1, only one base plate failed while the rotation in the other essentially stopped increasing. For test 2, both base plates failed but not at the same rate. It can be seen that the initial stiffness values are similar for all moment-rotation curves.

The results obtained using Method 2 are shown in Fig. 9 (b) for all fifteen tests. The bending moment $\mathrm{M}_{\mathrm{b}}$ is in this case determined from Eq. (11). It can be observed that the initial stiffness values are similar for axial loads greater than $100 \mathrm{kN}$. The tests were paused at the maximum bending moment to obtain the maximum static moment. These pauses can be seen 
on the $150 \mathrm{kN}$ and $200 \mathrm{kN}$ axial load test curves where the load drops at the maximum bending moment. In all tests, the rotational restraint of the concrete block forced both base plates to fail.

Due to looseness in the system, initial rotations of the uprights were recorded when applying the axial load. The axial load gradually closed pre-existing gaps causing all components of the base plate assembly to be in full contact. The curves in Fig. 9 were shifted on the horizontal axis to have the initial part of the curve passing through the origin.

\section{Maximum bending moment}

In the EN 15512 [5] Specification, the base plate stiffness is calculated based on the characteristic failure moment $\left(\mathrm{M}_{\mathrm{k}}\right)$, which is derived from the maximum moments $\left(\mathrm{M}_{\mathrm{ti}}\right)$ of several or numerous tests. According to the EN 15512 [5] Specification, "the test component shall be deemed to have failed when (a) the applied test loads reach their upper limit, (b) deformations have occurred of such a magnitude that the component can no longer perform its design function.” It is also stated that observations shall be made until jack $\mathrm{n}^{0} 2$ load reaches a maximum.

However, tests results show that the load in jack $n^{0} 2$ may reach a maximum value before large deformations occur in the base plate and/or before a maximum bending moment is reached. Indeed, after jack $\mathrm{n}^{0} 2$ has reached its maximum load, the decreasing rate of the jack force $\mathrm{F}_{2}$ may not be sufficient to overcome the P- $\Delta$ effect in Eq. (11) and the moment in the base plate may still increase.

This is demonstrated in Fig. 10, in which the load in jack $\mathrm{n}^{0} 2$ is plotted against the moment applied to the base plate for the $33 \mathrm{kN}, 100 \mathrm{kN}, 150 \mathrm{kN}$ and $200 \mathrm{kN}$ axial load tests. It can be noticed that the moment applied to the base plate is still increasing when the lateral load reaches a maximum, this being more noticeable for low axial loads. For the $150 \mathrm{kN}$ and 200 $\mathrm{kN}$ axial load tests, the bending moment corresponding to the lateral load reaching a maximum is about 5 to $10 \%$ less than the maximum bending moment. The point at which the lateral load reaches its maximum is therefore not a good indicator for when the maximum moment capacity of the base plate assembly is reached.

For the $200 \mathrm{kN}$ axial load tests, it can be also noticed that the P- $\Delta$ effect significantly affects the moment when applying the axial load (jack ${ }^{0} 1$ ) at the beginning of the test. The assembly moves sideway, thus inducing initial moments, as shown in Fig. 10 (d). 
Maximum bending moments were only reached for the $150 \mathrm{kN}$ and $200 \mathrm{kN}$ axial load tests. These maximum bending moments correspond to the formation of inelastic local buckles in the upright, as shown in Fig. 11 (a).

In the $0 \mathrm{kN}, 33 \mathrm{kN}$ and $100 \mathrm{kN}$ axial load tests, failure was initiated by the formation of plastic hinge lines in the base plate, as shown in Fig. 11 (b). As deformations in the base plate increase, the base plate is still able to withstand load due to the development of tensile membrane stresses. Because of this membrane action, the $0 \mathrm{kN}$ and $33 \mathrm{kN}$ axial load tests were performed beyond 0.1 rad and no maximum bending moment was reached. The same phenomenon were reported by [8].

When no maximum bending moment can be reached, an alternative to the maximum moment $\left(\mathrm{M}_{\mathrm{ti}}\right)$ has to be found for calculating the base plate stiffness. Large deformations where the connection is considered not to fail have been encountered by Kosteski et al. [9] and Yura et al. [10]. Kosteski et al. [9] set the ultimate deformation limit to 3\% of the width of the rectangular hollow sections used or $3 \%$ of the diameter of the circular hollow sections used. This criterion corresponds approximately to 3 times the first yield deformation. Yura et al. [10] set the ultimate deformation limit to 4 times the first yield deformation. These coefficients of 3 or 4 are commonly used as indicators for whether a plastic hinge is able to occur and sustain plastic deformations. It is recommended that a deformation limit of 4 times the yield deformation be used as a criterion for determining the ultimate moment of base plate assemblies.

Fig. 12 (a) and (b) show examples of how to calculate the ultimate moment using a rotation limit equal to 4 times the first yield deformation. As shown in Fig. 12, the first yield deformation is calculated at the intersection between a line representing the elastic stiffness deformation and a line representing the plastic stiffness deformation.

\section{Discussion on base plate stiffness modeling}

\subsection{Serviceability base plate stiffness}

The RMI [4] Specification uses the following expression for the base plate stiffness in terms of the moment applied to the base plate $\mathbf{M}_{\mathrm{b}}$ and the base plate rotation $\theta_{\mathrm{b}}$ :

$$
M_{b}=\frac{1}{12} b d^{2} E_{c} \theta_{b}
$$

where $b$ and $d$ are the depth and width of the upright section respectively, and $E_{c}$ represents the Young's modulus of the floor, concrete in our case typically equal to 30,000 MPa. Eq. 
(12) is derived from Salmon et. al. [11] who considered the concrete deformation under the base plate, as shown in Fig. 3 (a), but not the deformation of the base plate assembly itself. Sarawit [12] improved the RMI Eq. (12) and proposed two formulae for determining the moment-rotation relation of the concrete floor, depending of the base plate geometry. For the base plate geometry of the tests reported herein, the following expression for the stiffness $k_{b}$ applies:

$$
M_{b}=k_{b} \theta_{b}=\frac{7}{25} b d^{2} E_{c} \theta_{b} \Rightarrow k_{b}=\frac{7}{25} b d^{2} E_{c}
$$

The rotation of the upright itself occurring over the length of the base plate assembly, as shown in Fig. 3 (c), may be determined from Eq. (14), which is based on a single cantilever beam with a lateral point load $\mathrm{F}$ at the top as given in Fig. 13; i.e. a system that is statically equivalent to the EN 15512 [5] Specification base plate test set-up. The first order stiffness $k_{u}$ of the base plate assembly is given by:

$$
\left.\begin{array}{l}
M_{b}=F \frac{L}{2} \\
\theta_{b}=\frac{F a}{2 E I}(L-a)
\end{array}\right\} \Rightarrow M_{b}=k_{u} \theta_{b}=\frac{E I L}{(L-a) a} \theta_{b} \Rightarrow k_{u}=\frac{E I L}{(L-a) a}
$$

where E and I are the Young's modulus and the second moment of area of the upright section, respectively, $\mathrm{L}$ is twice the length of the tested upright including the rigid hinge on top of the upright (see Fig. 6) and a is the location of the transducers where the base plate assembly rotation is calculated. By determining the rotation of the upright itself at the same location as the transducers in Fig. 5, $k_{\mathrm{u}}$ allows comparing the stiffness of a fixed upright at its base to the base plate test stiffness results. Values of the upright characteristics and base plate test set up dimensions are summarized in Table 1.

To consider both the deformation of the concrete floor and the rotation of the upright, $\mathrm{k}_{\mathrm{b}}$ is reciprocally added to $\mathrm{k}_{\mathrm{u}}$ as:

$$
k_{b u}=\frac{1}{\frac{1}{k_{b}}+\frac{1}{k_{u}}}
$$

The stiffness lines for $k_{\mathrm{u}}$ and $\mathrm{k}_{\mathrm{bu}}$ are plotted against the averaged experimental test results in Fig. 14 (a), obtained using method 2 as experimental set-up. Little difference can be noticed between $k_{b u}$ and $k_{u}$ because the stiffness $k_{b}$ proposed by Sarawit (Eq. 13) is high compared to $k_{\mathrm{u}}$. Both $\mathrm{k}_{\mathrm{bu}}$ and $\mathrm{k}_{\mathrm{u}}$ give good approximations to the observed base plate initial stiffness, particularly at high levels of axial load. This implies that the initial deformation of the base 
plate assembly consists primarily of the contributions shown in Fig. 3 (a) and (c). For serviceability limit state calculations, it is likely that base plate assemblies will deform in their elastic range and $\mathrm{k}_{\mathrm{bu}}$ may be used for determining global serviceability deformations.

\subsection{Ultimate limit state design base plate stiffness}

Godley [8] has shown that increasing the base plate stiffness above a certain value does not increase the load carrying capacity of the rack, i.e. the rack may be considered to be fixed at the base. Godley proposes the following stiffness $k_{h}$ for this limiting value,

$$
M_{b}=k_{h} \theta_{b}=\frac{E I}{h} \theta_{b} \Rightarrow k_{h}=\frac{E I}{h}
$$

where E, I and h are the Young's modulus, the second moment of area of the upright section and the distance from the floor to the first beam respectively.

$\mathrm{k}_{\mathrm{h}}$ is plotted against experimental test results in Fig. 14 (b) as are the design stiffness values $\mathrm{k}_{33 \mathrm{kN}}, \mathrm{k}_{100 \mathrm{kN}}, \mathrm{k}_{150 \mathrm{kN}}$ and $\mathrm{k}_{200 \mathrm{kN}}$ for the $33 \mathrm{kN}, 100 \mathrm{kN}, 150 \mathrm{kN}$ and $200 \mathrm{kN}$ axial loads respectively calculated by the bi-linear procedure specified in Section A.2.4.5.2 of the EN 15512 [5]. A typical distance from the floor to the first beam of $1200 \mathrm{~mm}$ is assumed for calculating $\mathrm{k}_{\mathrm{h}}$ in Fig. 14 (b).

For the particular base plate tested, it can be observed that, in the presence of axial load in the upright, the base plate stiffness $\mathrm{k}_{\mathrm{h}}$ is lower than the initial stiffness and the EN 15512 [5] design stiffness values. As stated by Godley [8], stiffness values greater than $\mathrm{k}_{\mathrm{h}}$ would yield similar frame load carrying capacities, and as $\mathrm{k}_{\mathrm{h}}$ is lower than the EN 15512 [5] design stiffness, designing the rack with fully fixed base plate assembly would produce an accurate frame load carrying capacity.

Thus, in terms of design and in the presence of axial load in the upright, $\mathrm{k}_{\mathrm{u}}$ being close to the initial stiffness and greater than $\mathrm{k}_{\mathrm{h}}$, a simple fixed boundary condition for the particular tested base plate assembly would give an accurate approximation for ultimate and serviceability limit states. This suggests that for similar base plate geometries, if experimental test results were not available, a fixed ended condition at the base can be used to predesign the loaded steel storage rack.

\section{Relationship between the upright width and the base plate assembly initial stiffness and strength}

This section investigates the relationship between the width of the upright and the base plate moment-rotation curves for base plate assemblies failing by the development of yield lines as 
shown in Fig. 11 (c) and (d). An analytical prediction of the moment-rotation curves of hotrolled steel columns welded to end plates and bolted to a concrete floor is given in the European Standard EN1993-1-8 [13]. This prediction is based on the component method published in [14-18]. Due to differences between the base plate configurations and deformation characteristics assumed in the EN1993-1-8 [13] and the present work; namely the bending of the bracket (figure 3 (b)), the bolted connection between the bracket and the upright, and the possible uplift of the upright, comparison is not made between EN1993-1-8 [13] predictions and the test results. Moreover, the predicted rotation of the base plate in the EN1993-1-8 [13] is calculated at the end plate which is inappropriate in storage racks base plate assemblies as detailed in Section 2.2. Therefore a Finite Element model of the base plate assembly is used in this paper for predicting the experimental base plate assembly test results and performing parametric studies.

\subsection{FE model}

The base plate test set-up presented in Section 3 is statically equivalent to a single cantilever upright fitted with a base plate at one end and with a rigid device at the other representing the hinge used in the experimental tests. The axial load $\mathrm{F}_{1}$ is applied at the top of the cantilever as is a lateral load $F_{2}$ to simulate the lateral jack $n^{\circ} 2$ as shown in Fig. 15 (a). The FE model is based on the test set-up shown in Fig. 15 (a) and is presented in Fig. 15 (b). The finite element software Strand7 [19] is used to analyse the structure using shell elements for both the base plate assembly and the upright.

The M12 bolts connecting the base plate assembly to the upright are modelled using $12 \mathrm{~mm}$ bars between the centres of the bolt holes, which are linked to the perimeter of each hole using rigid elements (see Fig. 15 (b)). The bolts are assumed not to transfer torsion and hence the torsional moment in the bars is released in the analysis.

At the interface between the base plate and the floor, contact elements allow the base plate to

lift up, yet displacements are fully restrained in all directions along the perimeter of the anchor bolts. Additionally, contact elements allow the end section of the upright to lift up from the base plate. The stiffness of the concrete floor is considered to be perfectly rigid and a perfect elastic-plastic material for the base plate assembly is used in the FEA with the nominal yield stress $\mathrm{f}_{\mathrm{y}}$ and Young's modulus E given in Table 2. The detailed FE model is reported in [20]. Non-linear geometric and material analyses are performed, in which the axial force $\mathrm{F}_{1}$ is first 
applied and then the lateral load $\mathrm{F}_{2}$ is progressively increased to represent the experimental procedure followed in Section 3.

The second order moment $\mathrm{M}_{\mathrm{b}}$ applied to the base plate assembly is given by,

$$
M_{b}=F_{2}\left(L_{U}+L_{R}\right)+F_{1} \Delta=F_{2} \frac{L}{2}+F_{1} \Delta
$$

where $L_{U}$ and $L_{R}$ are the lengths of the upright and the rigid device at the top of the upright, respectively, and $\Delta$ is the horizontal displacement at the top of the cantilever as shown in Fig. 15 (a).

\subsection{FE results}

Fig. 16 compares the FE results against the experimental test results for axial loads of $0 \mathrm{kN}$, $33 \mathrm{kN}$ and $100 \mathrm{kN}$. Similarly to the experimental tests, the rotation $\theta_{\mathrm{b}}$ of the upright is measured at the base plate assembly-upright interface in the FE model as,

$$
\theta_{b}=\frac{d_{1}-d_{2}}{d_{12}}
$$

where $d_{1}$ and $d_{2}$ are the vertical displacements of two nodes on the web of the upright and $d_{12}$ is the horizontal distance between the nodes.

Fig. 16 shows a good agreement between experimental test results and FE results for the $0 \mathrm{kN}$ axial load case and a reasonable agreement can be found for the strength for the $33 \mathrm{kN}$ and $100 \mathrm{kN}$ axial load cases. In addition, for the $33 \mathrm{kN}$ and $100 \mathrm{kN}$ load cases, the FE results provide a slightly higher initial moment-rotational stiffness (taken as the stiffness between moments applied to the base plates between $0 \mathrm{kN} . \mathrm{mm}$ and $1300 \mathrm{kN}$.mm for the $100 \mathrm{kN}$ axial load case and $0 \mathrm{kN} . \mathrm{mm}$ and $500 \mathrm{kN}$.mm for the $33 \mathrm{kN}$ axial load case), the difference being more noticeable for the $33 \mathrm{kN}$ axial load case.

For the $33 \mathrm{kN}$ and $100 \mathrm{kN}$ load cases, the FE results diverge from the experimental results by providing a higher moment-rotational stiffness after the initial rotation. Differences between FE and experimental results are likely due to the sliding of the M12 bolts connecting the upright and the base plate bracket which is not modelled in the FEA. Investigations by Baldassino et al. [21] showed that the connection between the base plate assembly and the upright influences greatly the base plate behaviour. Imperfections of the concrete surface which would influence the rotation of the base plate while testing are also likely to explain the observed differences between FE and experimental results, as is the elasticity of the concrete floor which is not included in the FE model. Preliminary tests, not reported herein, show that imperfections of the concrete surface mainly influence the strength of the base plate. 
The main purpose of this section is to draw general conclusions about the initial momentrotational stiffness and strength of base plates using simple FE analysis. Ignoring the momentrotation behaviour after the initial deformation, the FE model presented herein is found to satisfactory reproduce the experimental test results in terms of initial moment-rotation stiffness and strength.

Fig. 17 shows the deformed shape at failure for the $33 \mathrm{kN}$ axial load case, as obtained from the FE analysis. The deformed shape is similar to that observed in the experimental tests, as shown in Fig. 11 (c) and (d).

\subsection{FE results for different upright widths}

To investigate the base plate behaviour over a wider range of upright sizes, additional analyses were carried out on $90 \mathrm{~mm}$ and $150 \mathrm{~mm}$ wide uprights. The geometries of these, not including the thickness, were determined by a direct scaling of the previously analysed geometry corresponding to a width of $125 \mathrm{~mm}$. The geometry of the associated base plate assemblies is also determined by direct scaling of the previously analysed geometry. In practice the thickness and the height of the base plate assembly is independent of the upright width and is kept to $5 \mathrm{~mm}$ and $150 \mathrm{~mm}$, respectively, for all upright widths in this study.

Moment-rotation curves are obtained for $0 \mathrm{kN}, 33 \mathrm{kN}$ and $100 \mathrm{kN}$ axial load cases as shown in Fig. 18 (a) and (b). The results show that the initial stiffness is independent of the upright width for the $0 \mathrm{kN}$ axial load cases but varies with the upright width for the $33 \mathrm{kN}$ and $100 \mathrm{kN}$ axial load cases. The strength is dependent on the upright width for all axial load cases.

The initial stiffness and base plate strength (taken as the moment applied to the base plate assembly at $0.05 \mathrm{rad}, 0.015 \mathrm{rad}$ and $0.005 \mathrm{rad}$ for $0 \mathrm{kN}, 33 \mathrm{kN}$ and $100 \mathrm{kN}$ axial load cases respectively) are reported in Table 3. For the $33 \mathrm{kN}$ and $100 \mathrm{kN}$ load cases (in the presence of axial load in the upright), a mainly cubic relationship is found between the base plate initial stiffness and the width of the upright as shown in Fig. 19 (a). For all load cases, the base plate strength is found to be essentially proportional to the width of the upright as shown in Fig. 19 (b).

When a base plate is subjected to an axial load, the axial load locks the base plate flat on the ground until the overturning moment overcomes the stabilising moment produced by the axial force; a phenomenon which has been further studied in [3, 22]. As a result, in the presence of an axial load in the upright, the initial deformation is mainly related to the associated bending of the base plate bracket and of the upright as shown in Fig. 3 (b) and (c). The initial 
deformation is then a function of the second moments of area of the bracket $\mathrm{I}_{\text {Bracket }}$ and the upright $\mathrm{I}_{\text {Upright }}$. As the bracket and the upright depths are proportional to the bracket and upright widths respectively, $\mathrm{I}_{\mathrm{Bracket}}$ and $\mathrm{I}_{\text {Upright }}$ are consequently proportional to the cube of the upright width. However, experimental results in Section 5.1 tend to show that the bracket contribution (Fig. 3 (b)) in the global initial deformation of the base plate assembly is significantly less than the upright contribution (Fig. 3 (c)).

For the $0 \mathrm{kN}$ axial load case, the base plate is not locked flat on the ground and the initial deformation is mainly related to the base plate elastically uplifting from the ground on one side as shown in Fig. 3 (d).

The base plate assembly strength is related to the development of yield lines in the base plate and is then a function of the base plate geometry as developed in a simple analytical model in [20].

\section{Conclusions}

This paper clarifies and explains the base plate test set-up proposed in the EN15512 [5] Specification for measuring the stiffness and strength of steel storage rack base plates. An appropriate location of the transducers is proposed for best capturing the base plate behaviour. Inconsistencies in the EN15512 Specification result in two approaches to the test set-up, both set-ups are tested in this paper resulting in one method being deemed superior to the other by allowing both base plates to fail without triggering catastrophic failure. It is therefore recommended to perform the test following this method.

When base plate tests do not reach a maximum moment, a deformation limit criteria can be used to calculate the maximum bending moment. It is proposed herein that a deformation limit of four times the yield deformation limit is appropriate for determining the ultimate moment from base plate tests.

From the experimental test results, it appears that the initial stiffness of base plate connections is derived mainly from the bending of the upright and the elastic deformation of the floor. For the particular base plate assembly tested, considering a fully fixed boundary condition for the base plate would give satisfactory results for preliminary design for both the frame load carrying capacity and serviceability deformations in the presence of axial load in the upright. FE results show that in presence of axial load in the upright, the initial moment-rotation stiffness of the base plate assembly is proportional to the cube of the upright width whereas the base plate assembly strength is proportional to the upright width. When no axial load is 
applied to the upright, the moment-rotation initial stiffness of the base plate assembly is independent of the upright width whereas the strength is still proportional to the upright width. These relationships are useful for design where base plate tests may be performed for a particular upright width. The relationships allow moment-rotation curves for other upright widths to be evaluated from the test results, consequently reducing the design cost by avoiding additional laboratory tests.

\section{Acknowledgements}

The authors would like to thank Dr Murray Clarke from Dematic Pty Ltd for his comments and for making the Dematic software RAD available. Also thanks to Dr Lip Teh from the University of Wollongong for his comments. The authors gratefully acknowledge the financial support provided by the Australian Research Council through Discovery Project Grant DP0559983.

\section{References}

[1] N. Baldassino, C. Bernuzzi, Analysis and behaviour of steel storage pallet racks, ThinWalled Structures, 37 (2000) 277-304.

[2] R.G. Beale, M.H.R. Godley, Problems arising with pallet rack semi-rigid base-plates, in: C.K. Choi, H.G. Kwak (Eds.) 1st International Conference on Steel and Composite Structures, Pusan, Korea, 2001, pp. 699-706.

[3] H.H. Lau, R.G. Beale, M.H.R. Godley, The influence of column base connectivity on the stability of columns and frames, in: R.G. Beale (Ed.) 6th International Conference on Steel and Aluminium Structures, Oxford, UK, 2007, pp. 425-432.

[4] RMI, Specification for the design, testing and utilization of industrial steel storage racks, in, Rack Manufacturers Institute, Charlotte, U.S.A., 2008.

[5] EN 15512, Steel static storage systems - Adjustable pallet racking systems - Principles for structural design, in, European Committee for Standardization (CEN), Brussels, Belgium, 2009.

[6] M.H.R. Godley, R.G. Beale, X. Feng, Rotational stiffness of semi-rigid baseplates, in: W.W. Yu, R.A. LaBoule (Eds.) 14th International Specialty Conference on Cold-Formed Steel Structures, St Louis, Missouri, U.S.A., 1998, pp. 323-335. 
[7] N. Baldassino, R. Zandonini, Industrial steel racks: tests, design and codes, in: G.J. Hancock, et al. (Ed.) International Conference on Advances in Structures, Sydney, Australia, 2003, pp. 229-235.

[8] M.H.R. Godley, The behaviour of storage racking baseplates, in: R.G. Beale (Ed.) 6th International Conference on Steel and Aluminium Structures, Oxford, UK, 2007, pp. 433-440.

[9] N. Kosteski, J.A. Packer, Welded Tee-to-HSS connections, Journal of Structural Engineering, 129 (2003) 151-159.

[10] J.A. Yura, N. Zettlemoyer, I.F. Edwards, Ultimate capacity equations for tubular joints, in: 12th Annual Offshore Technology Conference, Houston, USA, 1980, pp. 113-125, Paper 3690.

[11] S.G. Salmon, L. Schenker, B.G. Johnston, Moment rotation characteristic of column anchorages, Journal of the Structural Division, 81 (1955).

[12] A.T. Sarawit, Cold-formed steel frame and beam-column design, School of Civil and Environmental Engineering, Cornell University, 2003.

[13] EN 1993-1-8, Eurocode 3 Design of steel structures. Design of joints, in, European Committee for Standardization (CEN), Brussels, Belgium, 2005.

[14] M. Steenhuis, F. Wald, Z. Sokol, J. Stark, Concrete in compression and base plate in bending, HERON, 53 (2008) 51-67.

[15] N. Gresnigt, A. Romeijn, M. Steenhuis, F. Wald, Column bases in shear and normal force, HERON, 53 (2008) 87-108.

[16] F. Wald, Z. Sokol, J.-P. Jaspart, Base plate in bending and anchor bolts in tension, HERON, 53 (2008) 21-50.

[17] F. Wald, Z. Sokol, M. Steenhuis, J.-P. Jaspart, Component method for steel column bases, HERON, 53 (2008) 3-20.

[18] J.-P. Jaspart, F. Wald, K. Weynand, N. Gresnigt, Steel column base classification, HERON, 53 (2008) 69-86. 
[19] Strand7, Using Strand7 - User manual - Release 2.3.7, G+D Computing Pty Ltd, Sydney, Australia, 2005.

[20] B.P. Gilbert, K.J.R. Rasmussen, H. Zhang, Impact tests and parametric impact studies on drive-in steel storage racks, Research Report R903, School of Civil Engineering, The University of Sydney, Australia, 2009.

[21] N. Baldassino, A. Scandola, R. Zandonini, Performance of base-plate connections of steel storage pallet racks, in: K.J.R. Rasmussen, T. Wilkinson (Eds.) 5th International Colloquium on Coupled Instabilities in Metal Structures, The University of Sydney Sydney, Australia, 2008, pp. 119-130.

[22] H.H. Lau, M.H.R. Godley, R.G. Beale, The effect of column base connectivity on the carrying capacity of slender columns in: 9th International Conference on Steel and Space Structures, Singapore, 1999, pp. 397-405. 


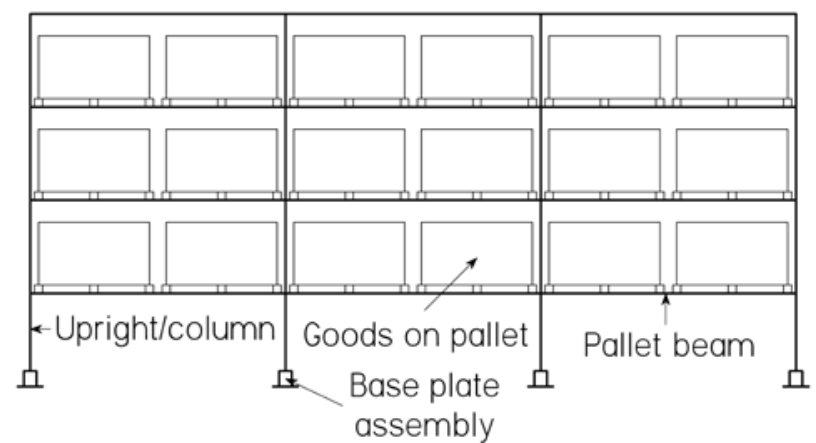

Fig. 1: Typical storage rack

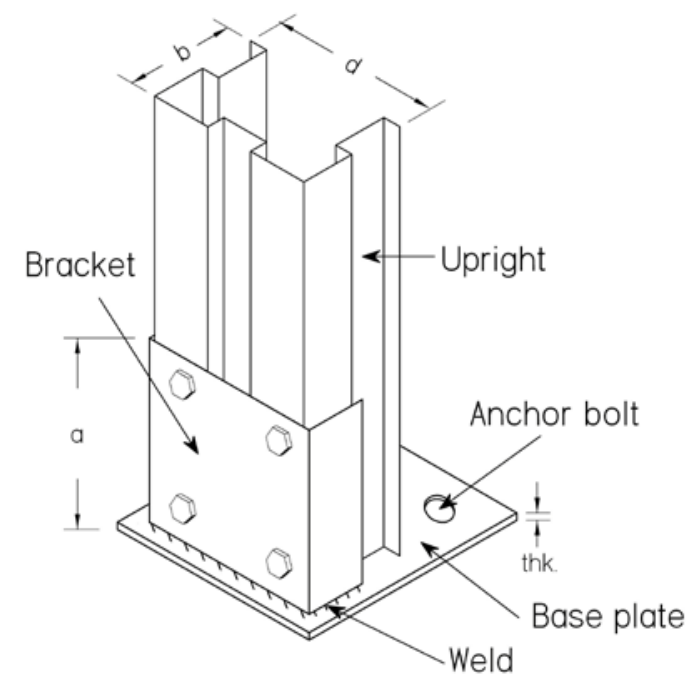

Fig. 2: Example of a base plate assembly

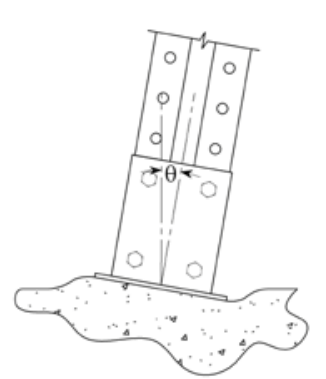

(a)

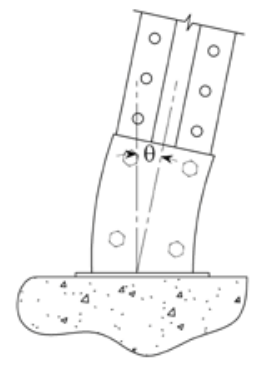

(b)

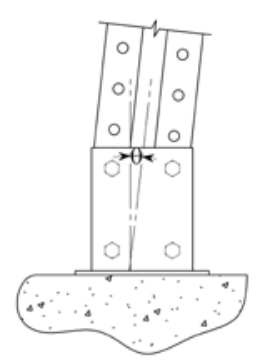

(c)

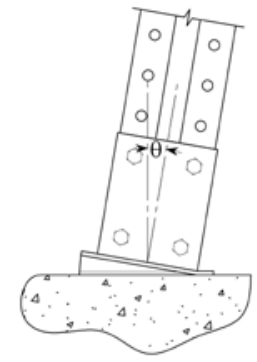

(d)

Fig. 3: Base plate assembly deformations, (a) concrete floor deformation, (b) bending of bracket, (c) bending and local deformation of upright, (d) combined yielding of the base plate and uplift of the assembly 


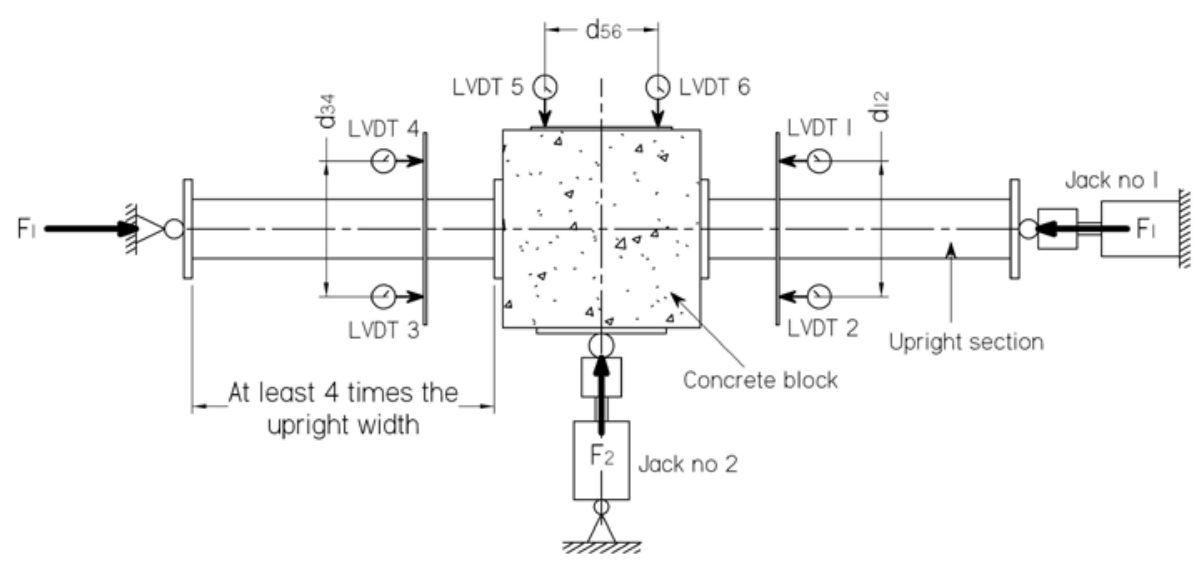

(a) - Plan view

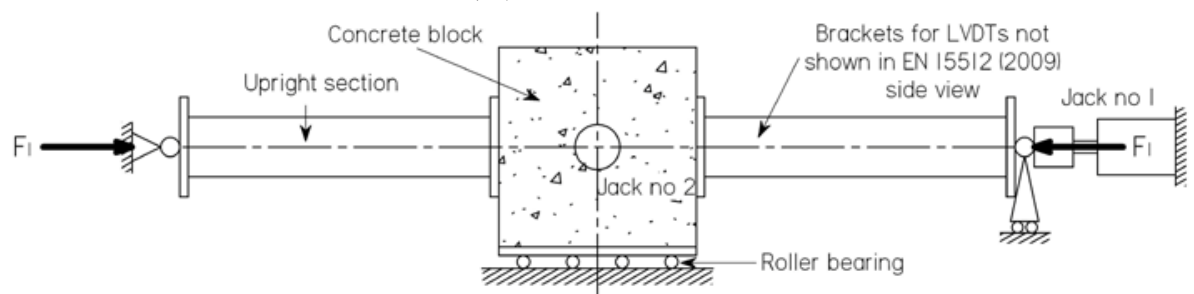

(a) - Side view

Fig. 4: Figure A.11 of the EN 15512 (2009) Specification, (a) plan view and (b) side view

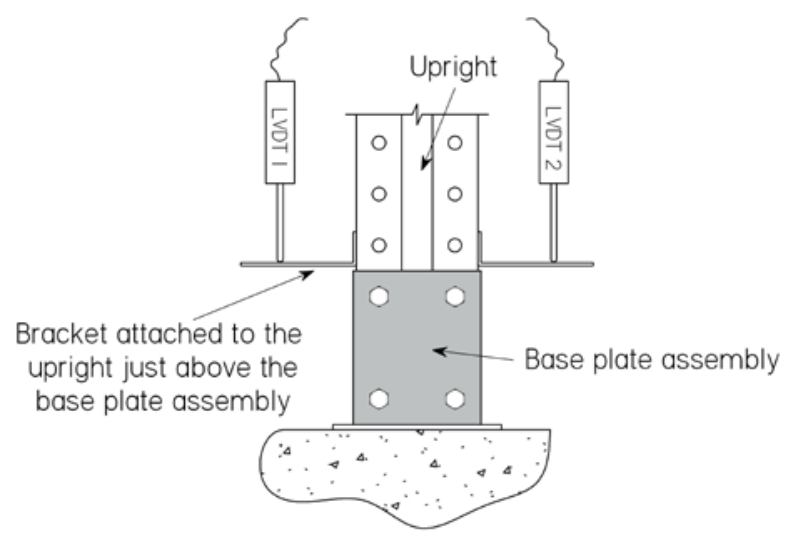

Fig. 5: Appropriate location of the displacement transducers 


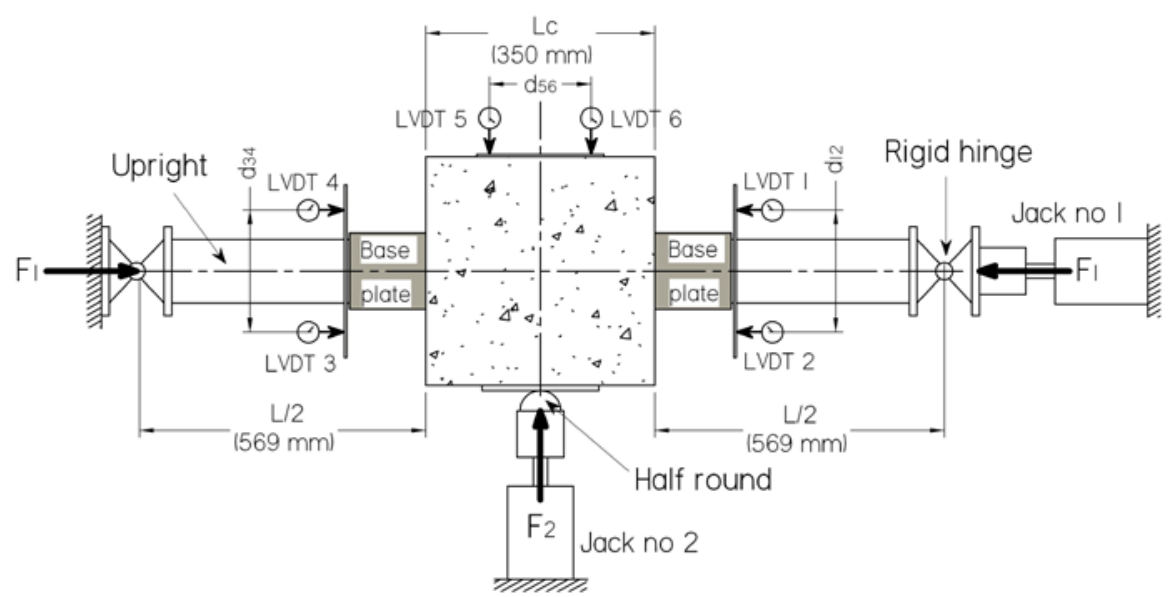

(a) - Method 1

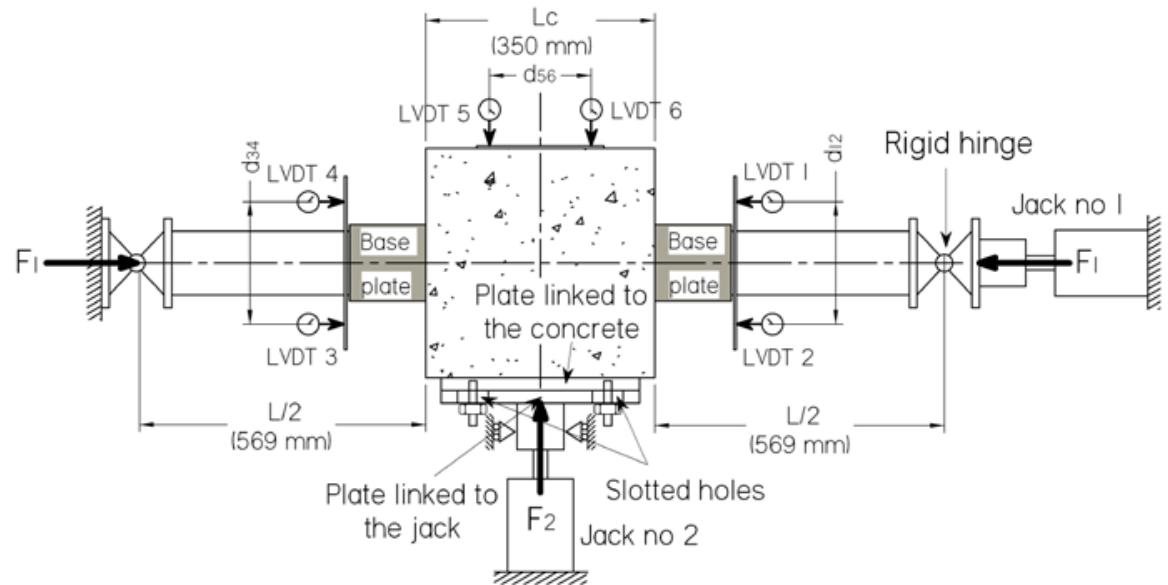

(b) - Method 2

Fig. 6: Plan view of test set-up for (a) Method 1 and (b) Method 2
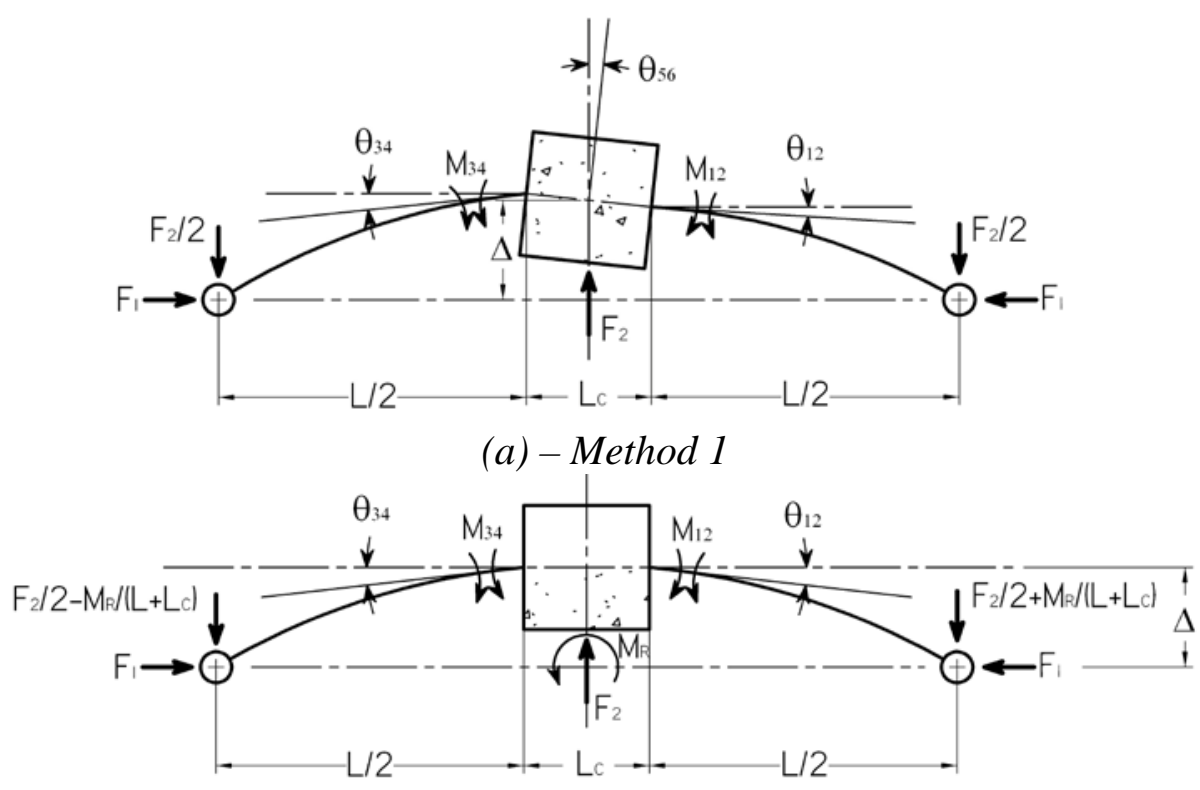

(b) - Method 2

Fig. 7: Forces and deflections for (a) Method 1 and (b) Method 2 


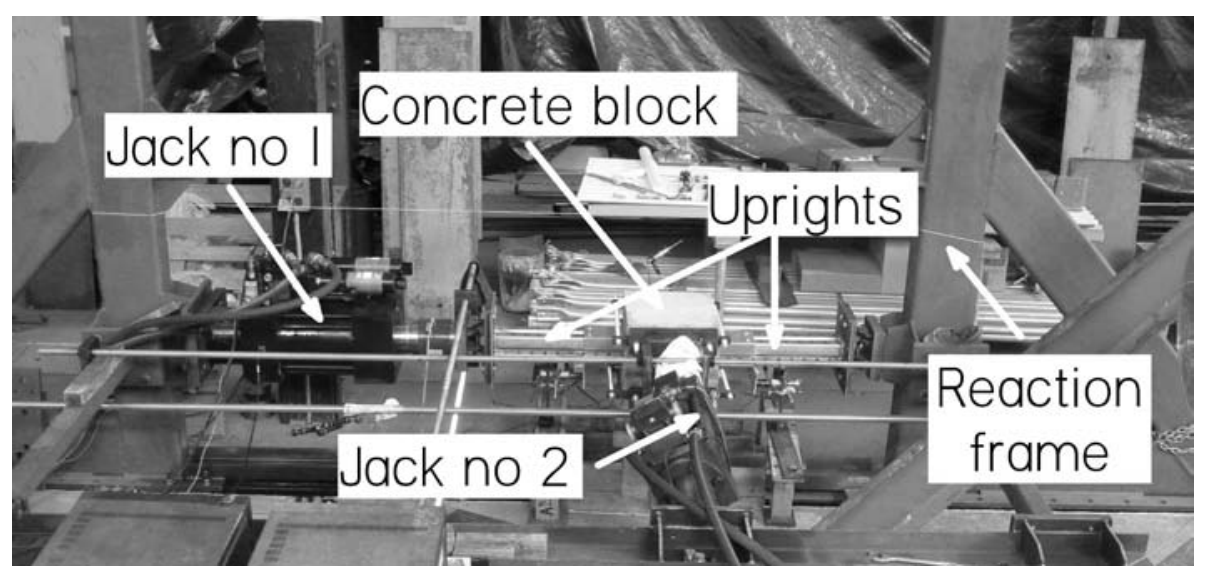

(a) - Test set-up

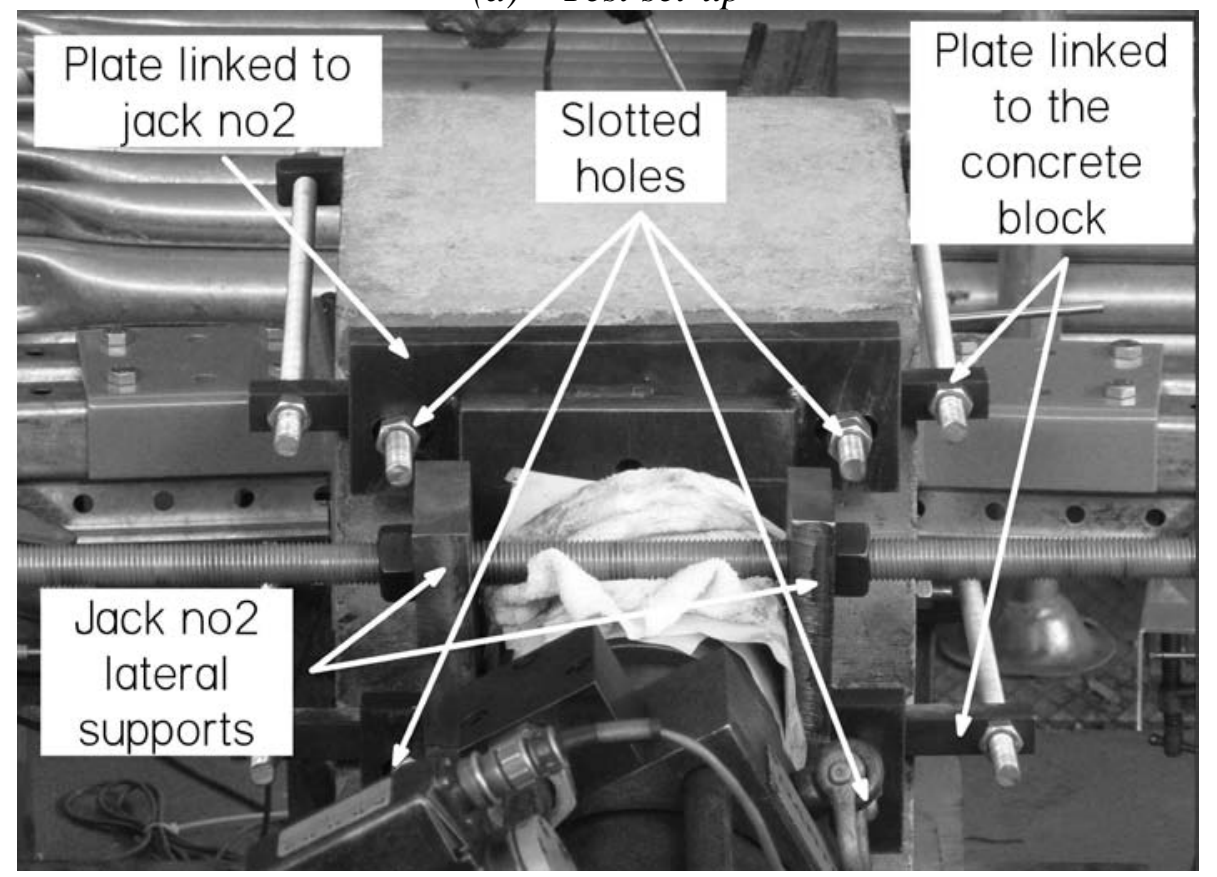

(b) - Restraining system

Fig. 8: Photographs of Method 2, (a) test set up and (b) restraining system 


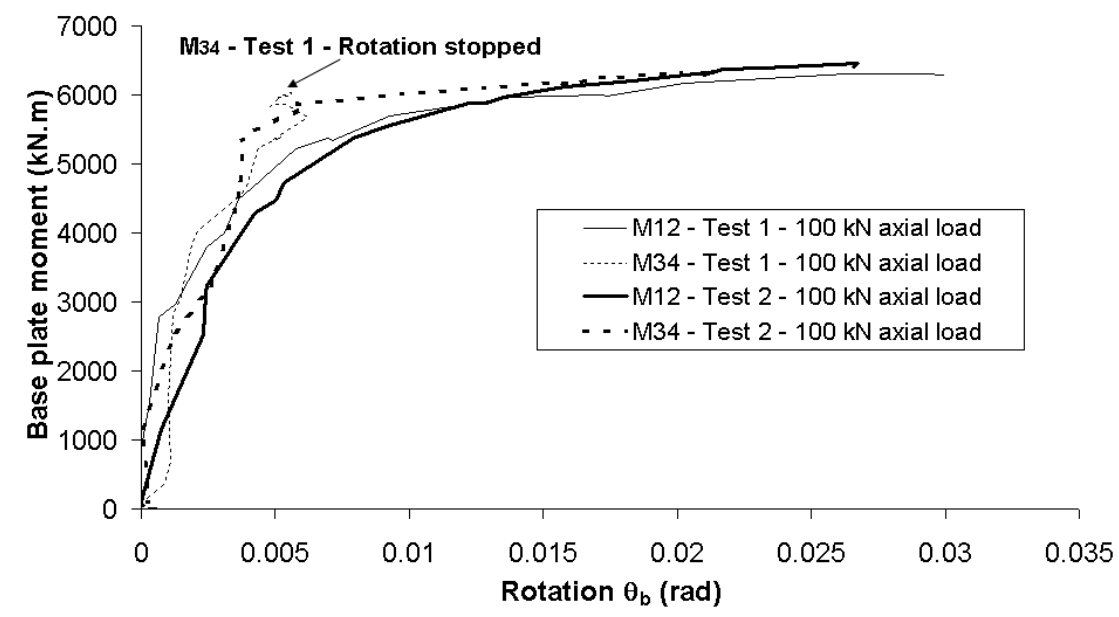

(a) - Method 1

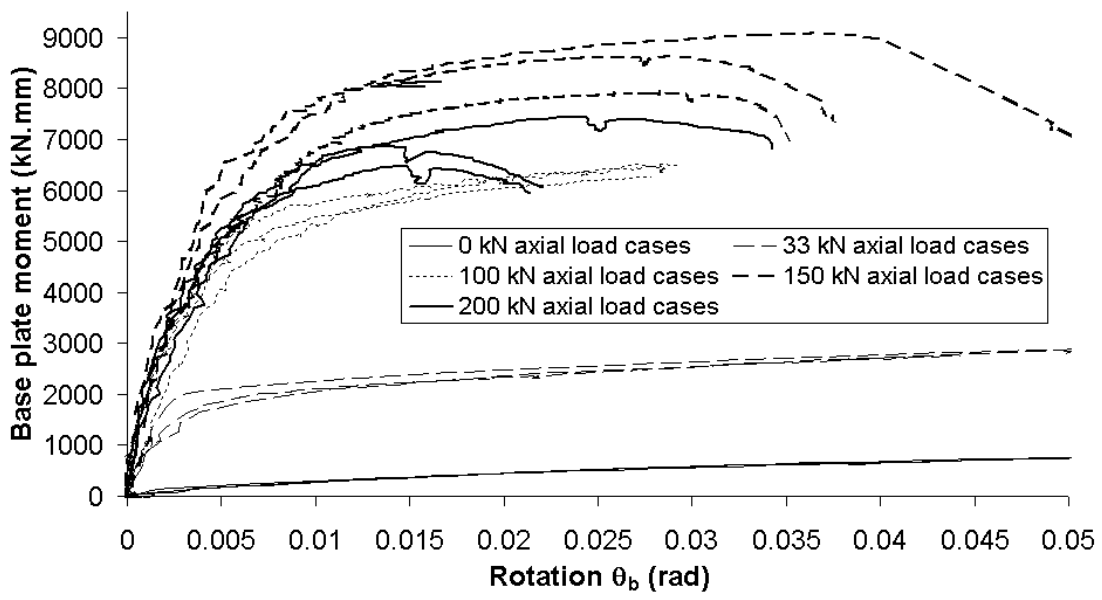

(b) - Method 2

Fig. 9: Moment-rotation curves from (a) Method 1, $100 \mathrm{kN}$ axial load case and (b) Method 2, all axial load cases 


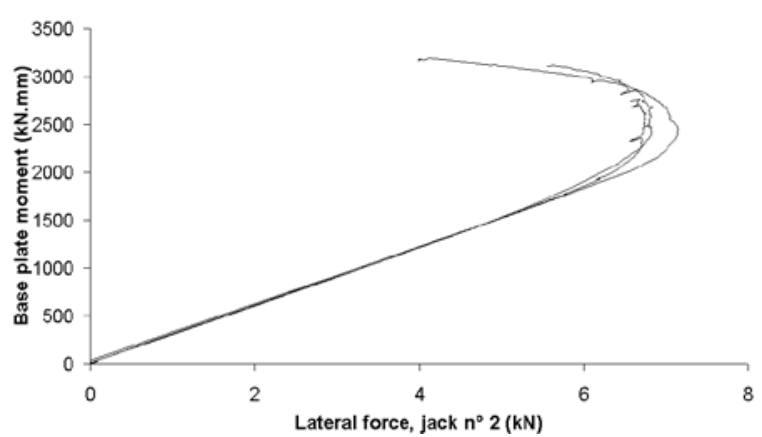

(a) -33 kN axial load

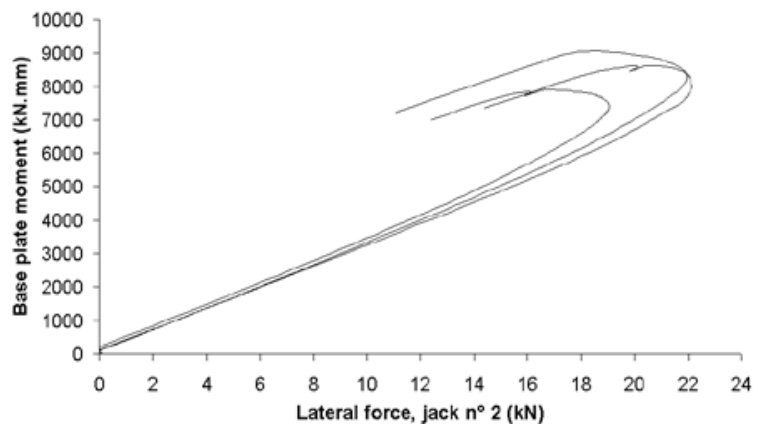

(c) $-150 \mathrm{kN}$ axial load

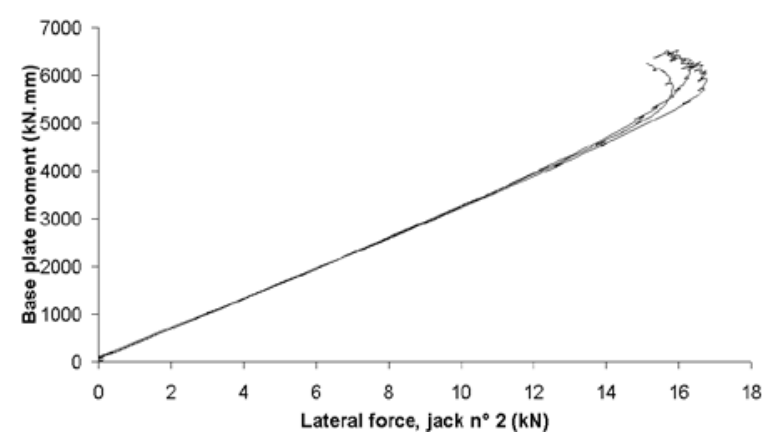

(b) $-100 \mathrm{kN}$ axial load

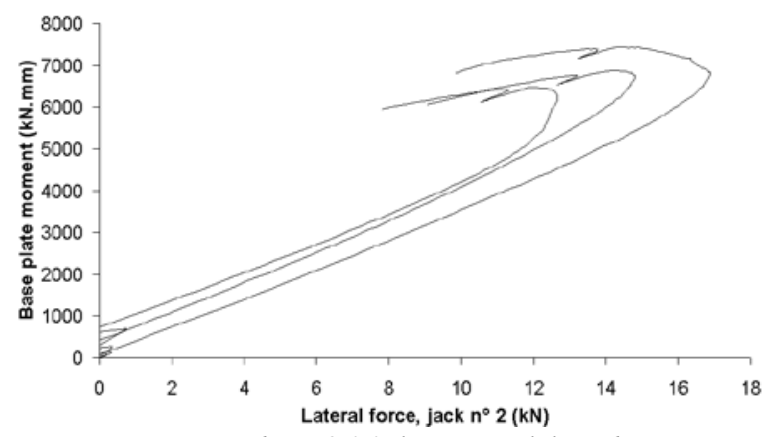

(d) $-200 \mathrm{kN}$ axial load

Fig. 10: Moment-lateral force curves for (a) $33 \mathrm{kN}$ axial force, (b) $100 \mathrm{kN}$ axial force, (c) 150 $\mathrm{kN}$ axial force and (d) $200 \mathrm{kN}$ axial force. Each figure contains the experimental curves for three nominally identical tests. 


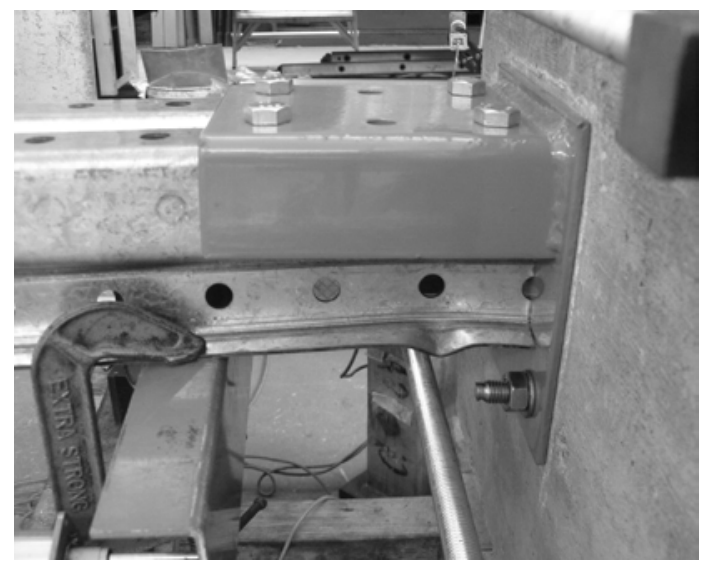

(a)

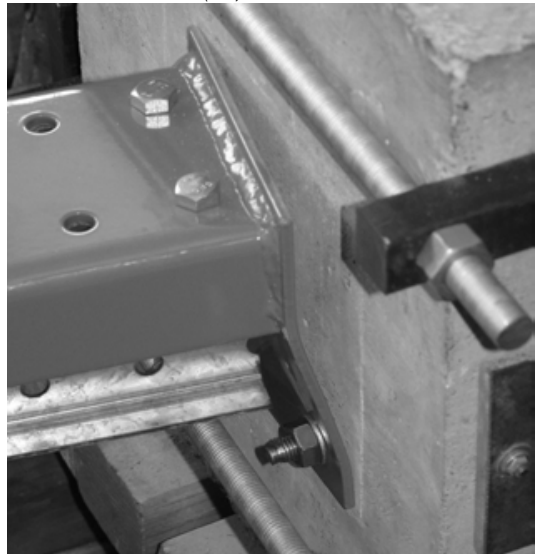

(c)

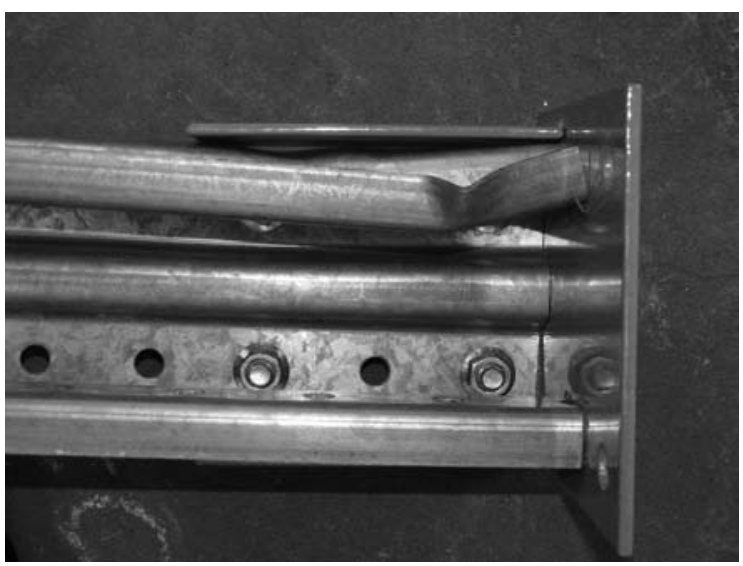

(b)

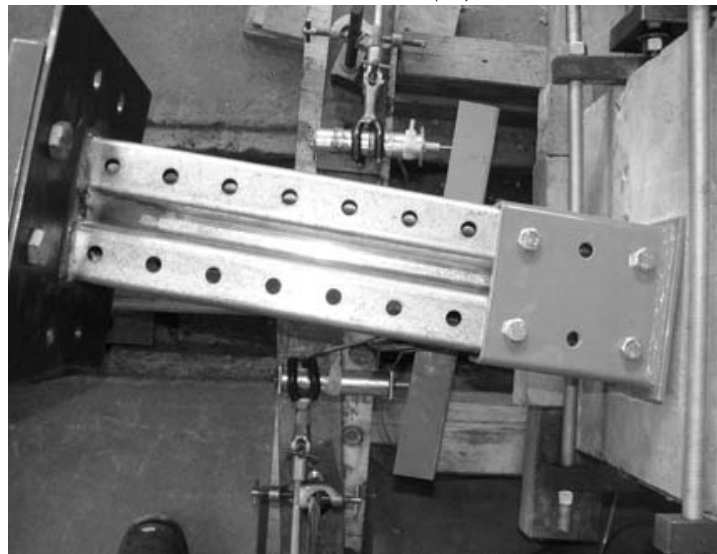

(d)

Fig. 11: typical failure mode for (a), (b) $150 \mathrm{kN}$ and $200 \mathrm{kN}$ axial load (local buckling) and (c), (d) $0 \mathrm{kN}, 33 \mathrm{kN}$ and $100 \mathrm{kN}$ (development of plastic hinges) 


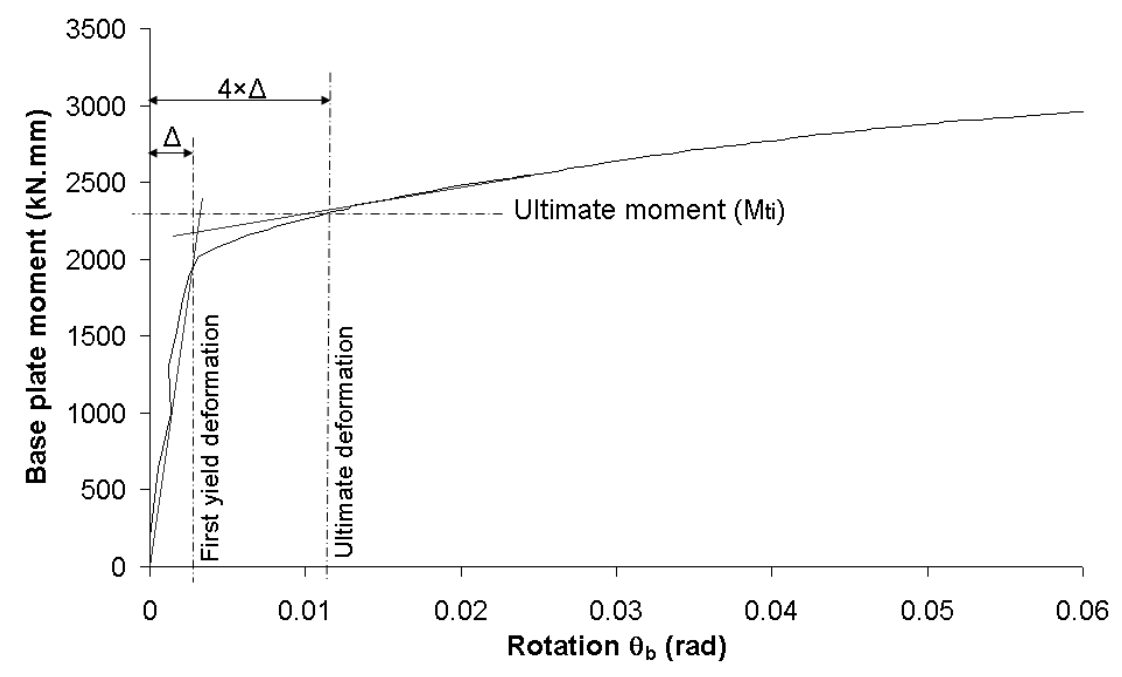

(a) $-33 \mathrm{kN}$ axial load

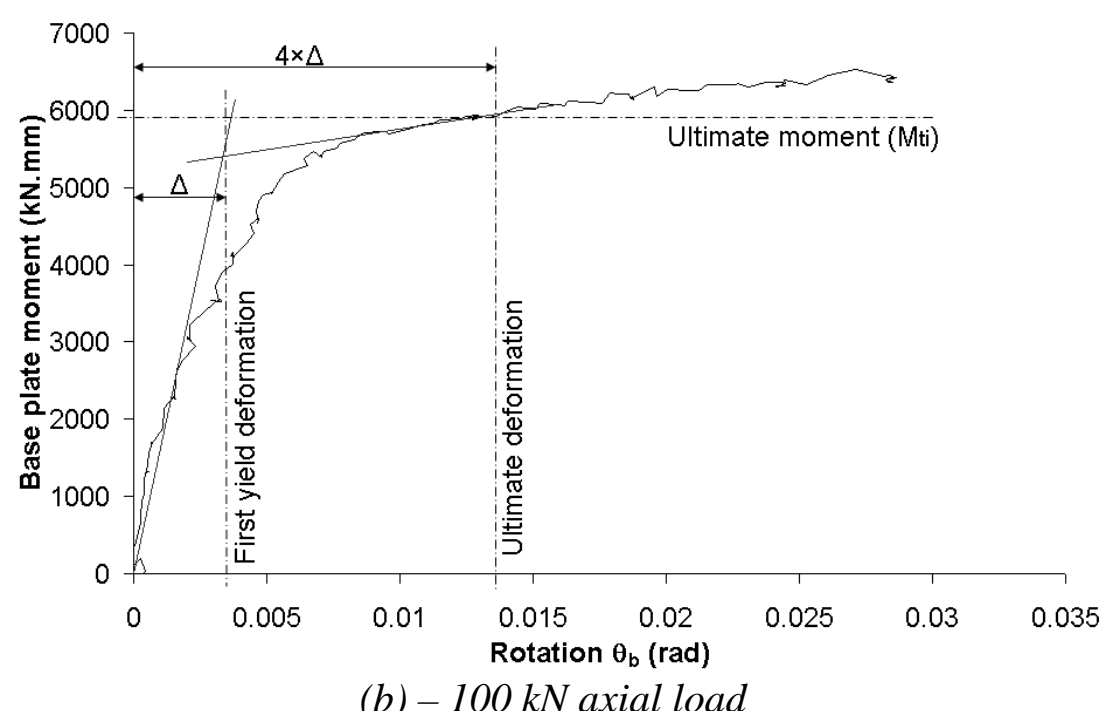

Fig. 12: Example on how to calculate the ultimate moment for (a) $33 \mathrm{kN}$ axial load and (b) $100 \mathrm{kN}$ axial load 


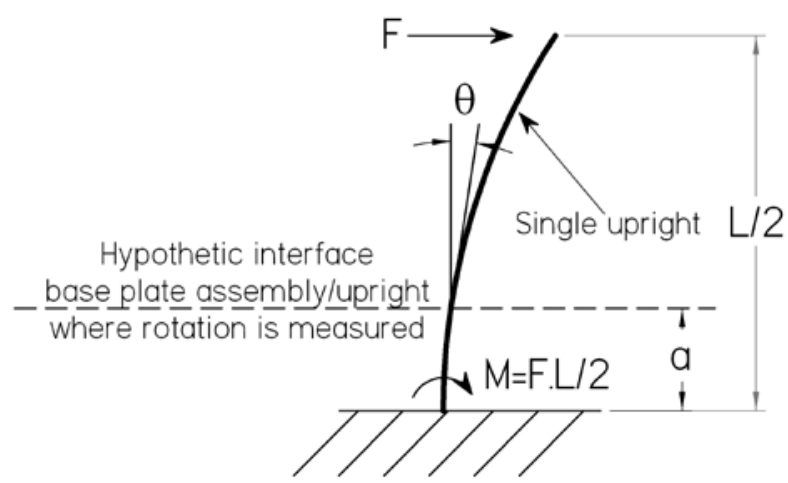

Fig. 13: Static of a single upright base plate test

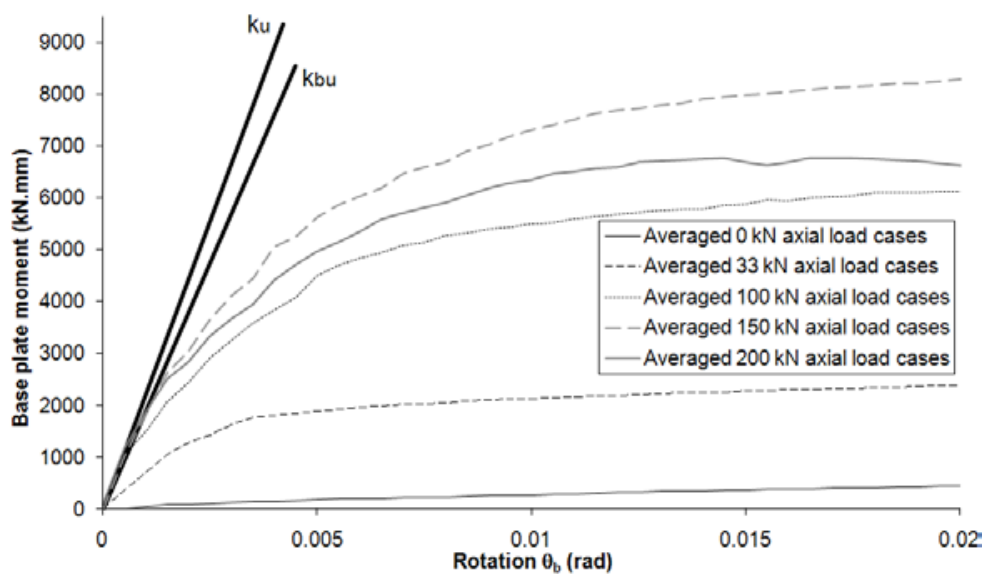

(a) - Averaged test results against $k_{u}$ and $K_{b u}$

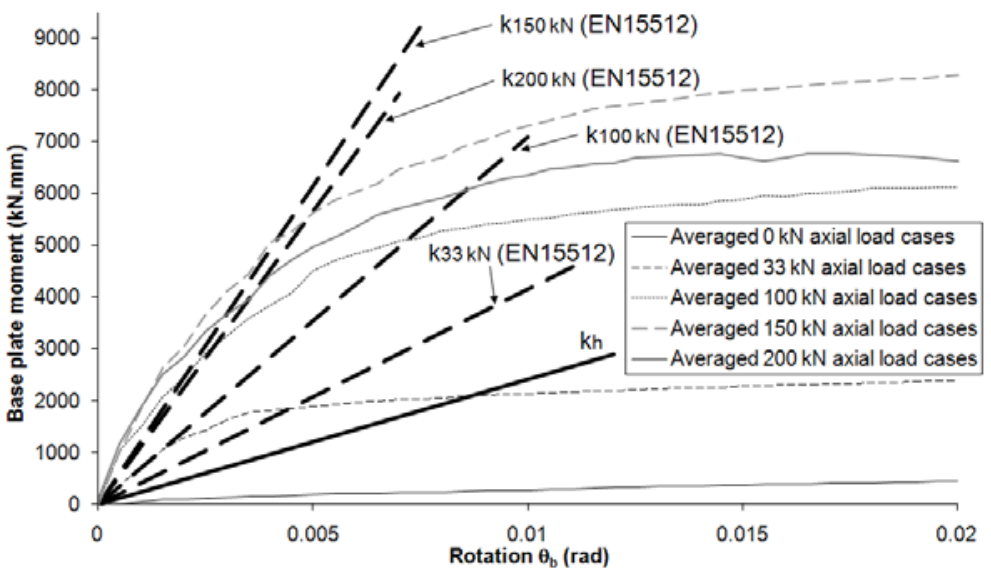

(b) - Averaged test results against EN 15512 and $k_{h}$

Fig. 14: Comparison of proposed stiffness (a) $k_{u}$ and $k_{b u}$, (b) EN 15512 and $k_{h}$ against the averaged test results over three tests per axial load case 


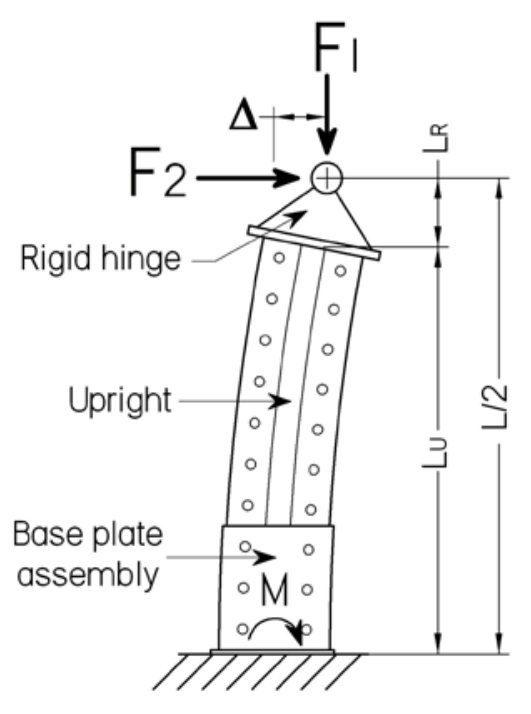

(a)

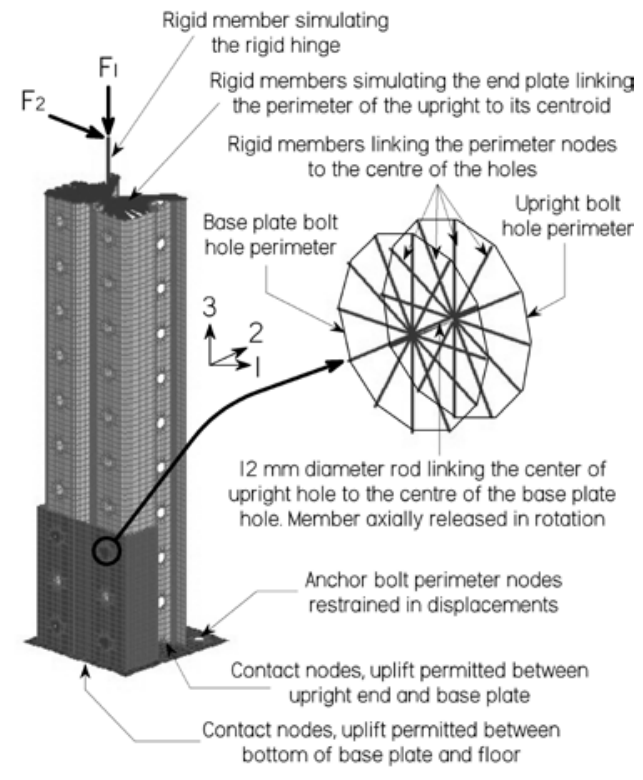

(b)

Fig. 15: Base plate model for FEA, (a) statically equivalent base plate test and (b) FE model

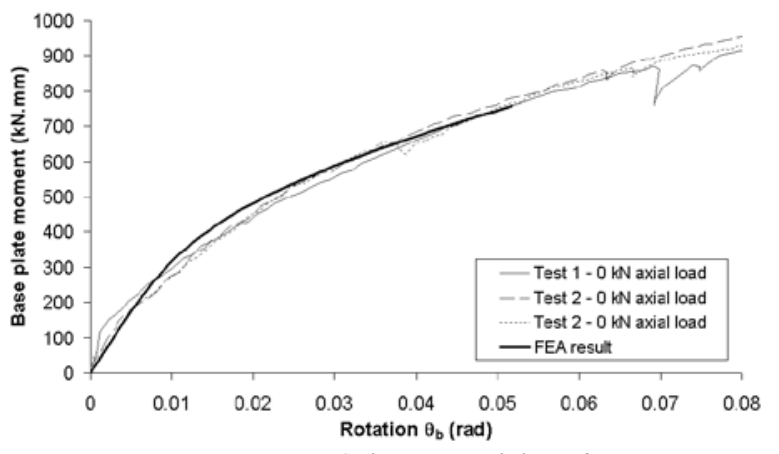

(a) $-0 \mathrm{kN}$ axial load

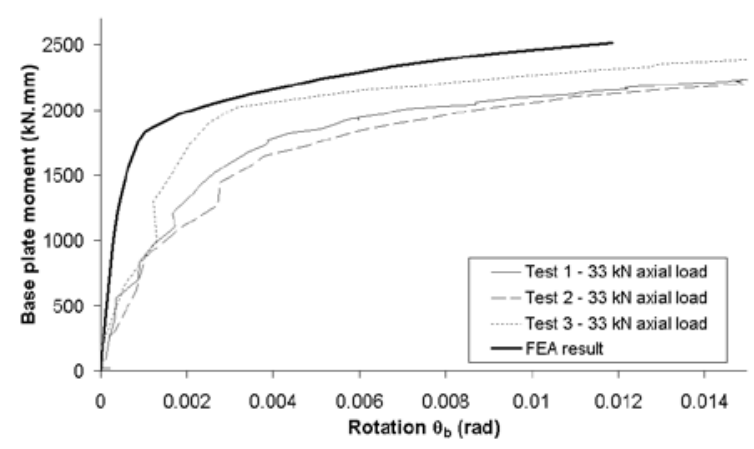

(b) $-33 \mathrm{kN}$ axial load

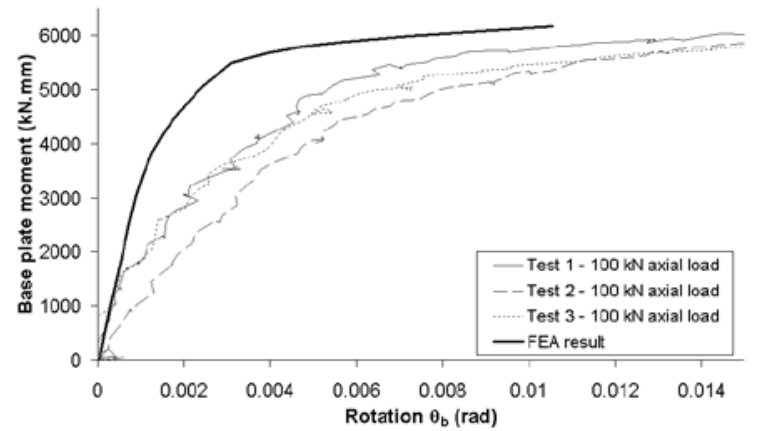

(c) $-100 \mathrm{kN}$ axial load

Fig. 16: Base plate test experimental test results and FE results for (a) $0 \mathrm{kN}$ axial load, (b) 33 $\mathrm{kN}$ axial load and (c) $100 \mathrm{kN}$ axial load 


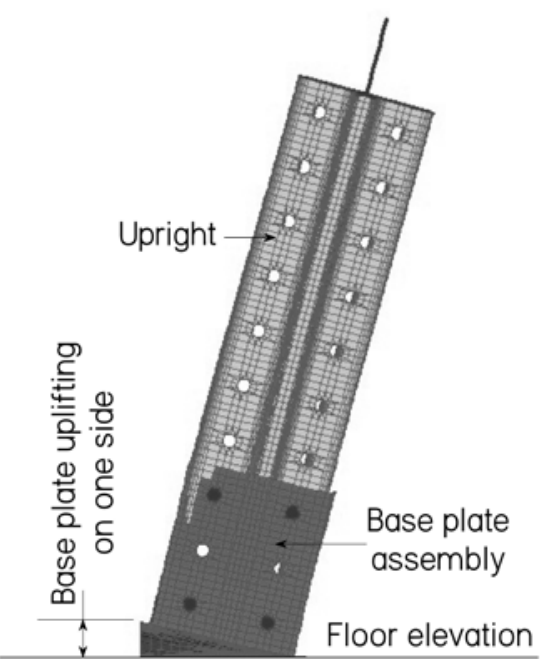

Fig. 17: FE deformed shape at failure for $33 \mathrm{kN}$ axial load (scale factor $=20)-$ front view 


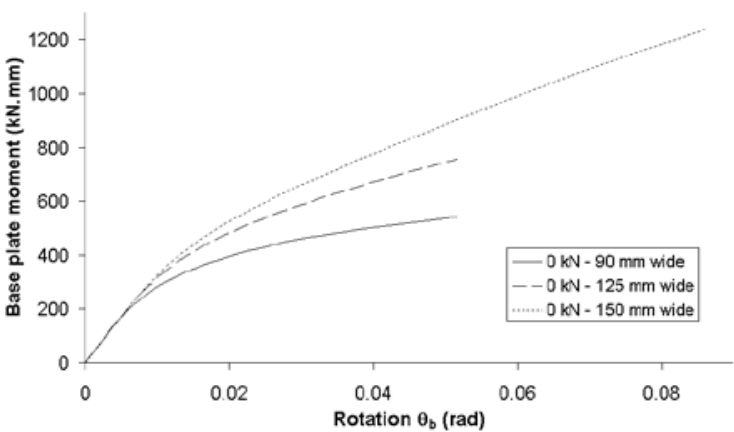

(a) $-0 \mathrm{kN}$ axial load

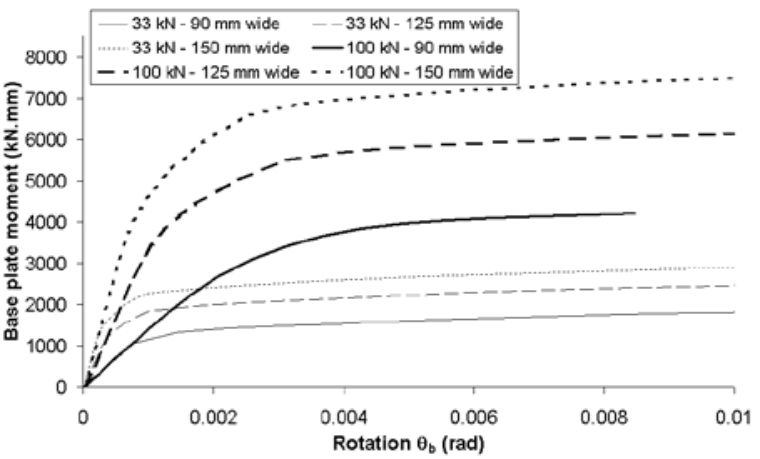

(b) $-33 \mathrm{kN}$ and $100 \mathrm{kN}$ axial loads

Fig. 18: FE results for different upright widths for (a) $0 \mathrm{kN}$ axial load, (b) $33 \mathrm{kN}$ and $100 \mathrm{kN}$ axial loads

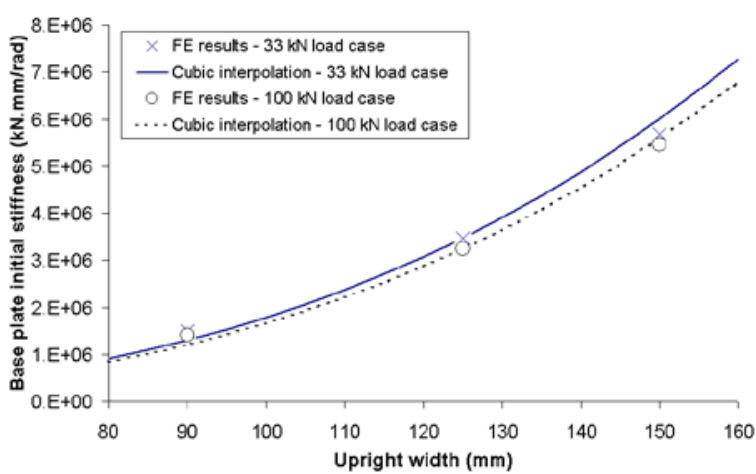

(a) - Initial stiffness

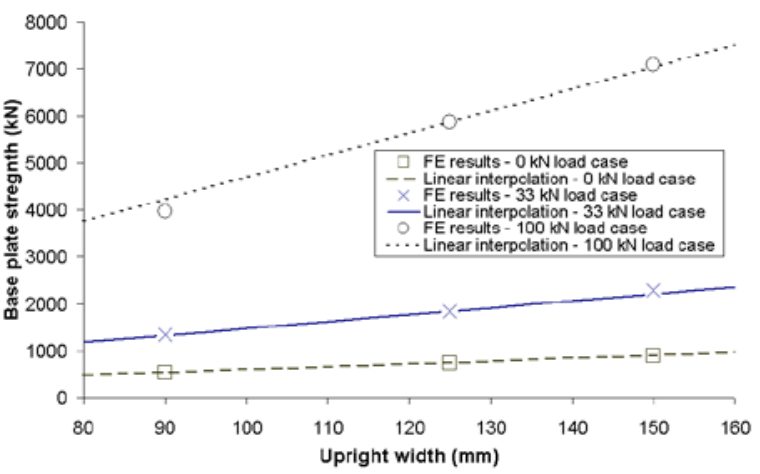

(b) - Strength

Fig. 19: Relationship between upright width and base plate assembly (a) initial stiffness and (b) strength 
Table 1

Upright section characteristic and base plate test dimensions

\begin{tabular}{llll|ll|ll}
\hline \multicolumn{2}{l|}{ Upright section characteristics } & & \multicolumn{2}{|l|}{$\begin{array}{l}\text { Base plate test } \\
\text { dimensions }\end{array}$} & \multicolumn{2}{l}{$\begin{array}{l}\text { Base plate assembly } \\
\text { dimension }\end{array}$} \\
\hline E (MPa) & $\mathrm{I}\left(\mathrm{mm}^{4}\right)$ & $\begin{array}{l}\text { Depth b } \\
(\mathrm{mm})\end{array}$ & $\begin{array}{l}\text { Width d } \\
(\mathrm{mm})\end{array}$ & L $(\mathrm{mm})$ & Lc $(\mathrm{mm})$ & $\begin{array}{l}\text { Height a } \\
(\mathrm{mm})\end{array}$ & Thk. (mm) \\
\hline 218325 & $1.33 \mathrm{e}+6$ & 98 & 125 & 1138 & 350 & 150 & 5 \\
\hline
\end{tabular}

Table 2

Base plate assembly characteristic and cantilever base plate test dimensions

Base plate assembly characteristics

\begin{tabular}{ll|ll}
\hline $\mathrm{E}(\mathrm{MPa})$ & Fy nominal $(\mathrm{MPa})$ & $\mathrm{L}_{\mathrm{U}}(\mathrm{mm})$ & $\mathrm{L}_{\mathrm{R}}(\mathrm{mm})$ \\
\hline 210000 & 250 & 500 & 69 \\
\hline
\end{tabular}

Table 3

Change in base plate assembly initial stiffness and strength (Numerical results for the three axial load cases

\begin{tabular}{l|lll|lll}
\hline \multirow{2}{*}{$\begin{array}{l}\text { Upright width } \\
(\mathrm{mm})\end{array}$} & \multicolumn{4}{l|}{ Initial stiffness (kN.mm/rad) } & \multicolumn{4}{l}{ Strength $(\mathrm{kN} . \mathrm{mm})$} & \\
\cline { 2 - 7 } & $0 \mathrm{kN}$ & $33 \mathrm{kN}$ & $100 \mathrm{kN}$ & $0 \mathrm{kN}$ & $33 \mathrm{kN}$ & $100 \mathrm{kN}$ \\
\hline 90 & 33860 & 1488763 & 1400170 & 537 & 1332 & 3960 \\
125 & 34898 & 3472616 & 3239005 & 745 & 1838 & 5867 \\
150 & 34404 & 5685256 & 5452952 & 885 & 2285 & 7097 \\
\hline
\end{tabular}

